\title{
SIMULASI ALIRAN FLUIDA PADA PROSES ENHANCED COALBED METHANE
}

\author{
Mohammad Resalto Pradewa1, Retno Gumilang Dewi*1, Ucok WR Siagian² \\ ${ }^{1}$ Kelompok Keahlian Perancangan dan Pengembangan Proses Teknik Kimia \\ Program Studi Teknik Kimia, Fakultas Teknologi Industri \\ 2Program Studi Teknik Pertambangan, Fakultas Pertambangan dan Perminyakan \\ Institut Teknologi Bandung \\ Jalan Ganesha 10 Bandung 40132 \\ Email: gelang@che.itb.ac.id, resalto.pradewa@yahoo.com
}

\begin{abstract}
Abstrak
Proses Enhanced Coalbed Methane (ECBM) dapat diterapkan sebagai salah satu teknologi penangkapan dan penyimpanan karbon (Carbon Capture and Storage atau CCS) untuk mitigasi emisi gas rumah kaca, dengan cara menyalurkan $\mathrm{CO}_{2}$ dari sumber emisi stasioner ke dalam reservoir lapangan ECBM. Integrasi CCS-ECBM ini merupakan teknologi baru yang diharapkan mampu mengurangi emisi $\mathrm{CO}_{2}$ sekaligus meningkatkan ketahanan pasokan energi Indonesia. Penelitian ini mempelajari aliran fluida pada retakan (fractures/cleats) di dalam reservoir CBM yang merupakan aliran laminer di bawah gradien tekanan yang mengikuti hukum Darcy. Penelitian ini bertujuan memahami mekanisme integrasi CCS dengan proses ECBM melalui pendekatan simulasi komputer. Senyawa-senyawa yang ditinjau adalah $\mathrm{CH}_{4}$ dan $\mathrm{CO}_{2}$. Variabel-variabel aliran yang diperhitungkan dalam model mencakup permeabilitas (k), porositas $(\phi)$, dan saturasi gas (S). Simulasi dilakukan menggunakan perangkat lunak FlexPDE versi 5 . Hasil simulasi menunjukkan bahwa mekanisme aliran dalam retakan dengan injeksi $\mathrm{CO}_{2}$ pada proses ECBM dipengaruhi oleh ketiga variabel yang ditinjau. Simulasi yang dijalankan selama 100 hari menunjukkan bahwa perolehan metana berbanding terbalik secara linier terhadap porositas, dengan perolehan sebesar $97,88 \%$ pada porositas 0,017 dan $37,16 \%$ pada porositas 0,63 .
\end{abstract}

Kata kunci: gas rumah kaca, CCS, ECBM, retakan, cleats

\begin{abstract}
The Enhanced Coalbed Methane (ECBM) process can be applied as a carbon capture and storage (CCS) technology for the mitigation of greenhouse gases emissions, by transferring $\mathrm{CO}_{2}$ emitted by stationary sources into ECBM field reservoirs. This CCS-ECBM integration is a novel technology that is aimed at reducing $\mathrm{CO}_{2}$ emission while simultaneously improving the energy supply security in Indonesia. This research studies the fluid flow in fractures/cleats in CBM reservoirs, which is a laminar flow under pressure gradient in accordance to Darcy's law. The objective of this research is to understand the mechanism of the integration between CCS and ECBM process via computer simulations. Gas components considered in the simulation include $\mathrm{CH}_{4}$ and $\mathrm{CO}_{2}$. Fluid flow variables in this research are permeability $(\mathrm{k})$, porosity $(\phi)$, and gas saturation (S). Simulations are done using the FlexPDE version 5 software package. Simulation results indicate that all three variables influence the fluid flow mechanism in fractures/cleats during the injection of $\mathrm{CO}_{2}$ in ECBM process. Simulations which are run for 100 days predict that methane recovery is inversely proportional to porosity, with a recovery of $97.88 \%$ at a porosity of 0.017 , and $37.16 \%$ at a porosity of 0.63 .
\end{abstract}

Keywords: greenhouse gases, CCS, ECBM, fractures, cleats

*korespondensi 


\section{Pendahuluan}

Peningkatan temperatur permukaan bumi secara global atau lebih dikenal dengan istilah pemanasan global telah mengakibatkan adanya perubahan iklim yaitu berubahnya kondisi fisik atmosfer bumi, antara lain suhu dan distribusi curah hujan yang membawa dampak luas terhadap berbagai sektor kehidupan manusia. Perubahan fisik ini tidak hanya terjadi sesaat, tetapi dalam kurun waktu yang cukup panjang. Perubahan ini terjadi karena adanya perubahan komposisi kimia gas-gas yang terdapat di atmosfer, yang disebut sebagai gas rumah kaca. Konsentrasi gas rumah kaca yang berlebihan di atmosfer akan berdampak pada perubahan pola iklim (meningkatkan frekuensi dan intensitas dari peristiwa ekstrim) serta gangguan ekologis dan ekosistem, kenaikan permukaan laut, dan sebagainya (Boer, 2000; Weart, 2008).

Karbondioksida merupakan gas yang berkontribusi cukup besar terhadap peningkatan konsentrasi gas rumah kaca. Salah satu penyebab utama meningkatnya konsentrasi karbondioksida di atmosfer adalah penggunaan bahan bakar fosil. Total emisi karbondioksidasecara global pada tahun 2009 adalah 31.3 miliar ton, atau meningkat sekitar 40\% sejak tahun 1990 (Olivier dan Peters, 2010). Di Indonesia, total emisi karbondioksida pada tahun 2000 adalah sebesar $940.879 \mathrm{Gg}$, atau $78 \%$ dari total emisi gas rumah kaca keseluruhan $(1.205 .753 \mathrm{Gg}$ $\mathrm{CO}_{2} \mathrm{e}$ ) (SNC, 2010). Salah satu teknologi yang dikembangkan untuk mengurangi emisi gas karbondioksida $\left(\mathrm{CO}_{2}\right)$ adalah Carbon Capture and Storage atau Carbon Capture and Sequestration (CCS). CCS adalah penangkapan $\mathrm{CO}_{2}$ dari sumber stasioner berskala besar, lalu ditransportasikan menuju lokasi tempat gas karbondioksida dapat diinjeksikan ke dalam formasi geologi bawah tanah (Kheshgi dkk., 2006). Lokasi penyimpanan geologis untuk proses CCS dapat berupa deep saline aquifers, lapangan minyak dan gas alami yang telah kosong atau habis, dan lapangan batubara (Kheshgi dkk., 2006).

Dengan semakin menurunnya produksi minyak bumi, Pemerintah RI melalui Peraturan Presiden Nomor 5/2006 mengenai sasaran bauran energi primer tahun 2025, ingin meningkatkan pemanfaatan sumber energi lainnya, termasuk sasaran proporsi gas alam dalam bauran energi primer sebesar $30 \%$. Peningkatan penggunaan gas alam untuk mencapai sasaran bauran energi primer tersebut dilakukan dengan pencarian sumbersumber gas alam yang potensial di Indonesia, termasuk juga sumber-sumber gas alam nonkonvensional seperti Coalbed Methane (CBM).

CBM adalah gas alam yang terjebak dalam lapisan batubara yang sampai saat ini belum banyak termanfaatkan meskipun potensinya di Indonesia yang cukup besar. Direktorat Jenderal Minyak dan Gas Bumi (2010) menyatakan bahwa sumber CBM di Indonesia sangat banyak dengan total kandungan sebesar 453,30 triliun kaki kubik, dengan sebaran terbesar berada di Sumatera, diikuti Kalimantan dan sedikit di Sulawesi dan Jawa Barat.

Dalam proses produksi CBM, injeksi gas ke dalam lapisan batubara dapat digunakan untuk meningkatkan perolehan (recovery) gas metan. Proses ini dikenal dengan istilah Enhanced Coalbed Methane (ECBM) recovery (Figueroa dkk., 2008). Hal ini memberikan peluang untuk melakukan integrasi CCS dengan ECBM. Menurut Figueroa dkk. (2008), gas karbondioksida dapat digunakan untuk diinjeksikan ke dalam lapisan batubara yang berfungsi meningkatkan perolehan gas metan. Dengan demikian, integrasi CCS dengan ECBM dapat menjadi salah satu solusi pemenuhan peningkatan kebutuhan akan energi dan juga pengurangan jumlah emisi karbondioksida dalam konteks mitigasi perubahan iklim.

Secara umum proses ECBM terdiri dari dua mekanisme utama. Pada proses injeksi dan penyimpanan karbondioksida di dalam lapisan batubara, mekanisme yang terjadi adalah peristiwa adsorpsi, sedangkan mekanisme pelepasan metan dari batubara adalah peristiwa desorpsi. Aliran gas yang terjadi pada lapisan batubara dibagi menjadi dua aliran, yaitu aliran Darcy dan aliran difusi. Aliran Darcy terjadi di sepanjang retakan (fractures/cleats) yang dipengaruhi oleh perbedaan tekanan dan permeabilitas retakan, sedangkan aliran difusi terjadi di dalam matriks batubara yang dipengaruhi oleh perbedaan konsentrasi (Gray, 1987; Law dkk., 2002).

Batubara memiliki kemampuan menyimpan gas dalam jumlah yang banyak, karena permukaannya mempunyai kemampuan mengadsorpsi gas. Meskipun batubara berupa benda padat dan terlihat seperti batu yang keras, tapi di dalamnya banyak sekali terdapat pori-pori yang berukuran lebih kecil dari skala mikron, sehingga batubara ibarat sebuah spon. 
Kondisi inilah yang menyebabkan permukaan batubara menjadi sedemikian luas sehingga mampu menyerap gas dalam jumlah yang besar. Jika tekanan gas semakin tinggi, maka kemampuan batubara untuk mengadsorpsi gas juga semakin besar (Raharjo, 2010).

Menurut Lemigas (2010), CBM adalah gas alam dengan dominan gas metana dan disertai oleh sedikit hidrokarbon lainnya dan gas non-hidrokarbon dalam batubara hasil dari beberapa proses kimia dan fisika. CBM sama seperti gas alam konvensional yang kita kenal saat ini, namun perbedaannya adalah CBM berasosiasi dengan batubara sebagai source rock dan reservoirnya. Sedangkan gas alam yang kita kenal saat ini, walaupun sebagian ada yang bersumber dari batubara, diproduksikan dari reservoir pasir, gamping maupun rekahan batuan beku. Di dalam lapisan batubara banyak terdapat rekahan (cleats), yang terbentuk ketika berlangsung proses pembentukan batubara. Melalui rekahan itulah air dan gas mengalir di dalam lapisan batubara. Adapun bagian pada batubara yang dikelilingi oleh rekahan itu disebut dengan matriks (coal matrix), tempat dimana kebanyakan CBM menempel pada pori-pori yang terdapat di dalamnya.

Proses produksi perolehan gas metan pada CBM secara konvensional dilakukan dengan memompa air keluar dan menurunkan tekanan reservoir, yang menghasilkan produksi gas metan sebesar $20-60 \%$ dari keseluruhan gas metan yang terkandung dalam reservoir (White dkk., 2005). Seperti pada kasus EOR, secara prinsip produksi primer dapat ditingkatkan dengan menginjeksikan $\mathrm{CO}_{2}$ pada lapangan batubara. Proses ini dinamakan ECBM Recovery (White dkk., 2005; Mazzotti dkk., 2009).

ECBM adalah teknik untuk meningkatkan perolehan gas metana dari produksi CBM. Karbondioksida $\left(\mathrm{CO}_{2}\right)$ apabila telah diinjeksikan ke dalam lapisan bawah tanah, maka akan terjerat sebagai sebuah gas tebal/padat dalam batubara, teradsorpsi pada batubara, dan terlarut dalam air formasi (Pini, 2009). Selain itu, karena $\mathrm{CO}_{2}$ lebih banyak mensubstitusi gas metana yang berada di dalam matriks, maka tingkat perolehan CBM juga meningkat (Raharjo, 2010). Hal ini menunjukkan bahwa integrasi CCS dengan cara injeksi $\mathrm{CO}_{2}$ pada proses peningkatan produksi CBM (ECBM) dapat dilakukan dan memberi hasil produksi yang lebih tinggi.
Tujuan dari penelitian ini adalah untuk memahami mekanisme integrasi CCS pada peningkatan produksi CBM melalui proses ECBM di dalam retakan lapisan batubara dan memperkirakan potensi penyimpanan $\mathrm{CO}_{2}$ serta potensi perolehan $\mathrm{CH}_{4}$ dalam lapangan CBM. Ruang lingkup dari penelitian ini yaitu mengkaji fenomena aliran fluida di dalam retakan pada proses peningkatan produksi CBM melalui injeksi karbondioksida, identifikasi faktor-faktor yang mempengaruhi injeksi $\mathrm{CO}_{2}$ pada proses ECBM, kelakuan senyawa gas metana dan karbondioksida, pemodelan matematik fenomena aliran fluida di dalam retakan pada proses ECBM dengan injeksi $\mathrm{CO}_{2}$, dan pengamatan efek injeksi $\mathrm{CO}_{2}$ serta efek saturasi gas terhadap injeksi $\mathrm{CO}_{2}$ pada proses ECBM.

\section{Metodologi}

Aliran gas dalam media berpori, khususnya pada bagian retakan lapisan batubara, umumnya dianalisa menggunakan hukum Darcy, yang menyatakan bahwa kecepatan Darcy gas, $u_{g}$, adalah berbanding langsung terhadap gradien tekanan gas, $\nabla P_{g}$, dan permeabilitas gas, $k_{g}$. Hukum Darcy dapat dituliskan sebagai berikut:

$\bar{u}_{g}=-\frac{k_{g}}{\mu_{g}}\left(\nabla P_{g}-\rho_{g} \bar{g}\right)$

dimana $\mu_{g}$ adalah viskositas gas dan $g$ adalah konstanta gravitasi. Dalam terminologi flux massa, bentuk persamaan adalah:

$\bar{F}_{g}=\rho_{g} \bar{u}_{g}=-\frac{k_{g}}{\mu_{g}} \rho_{g}\left(\nabla P_{g}-\rho_{g} \bar{g}\right)$

Hukum Darcy dapat dipakai pada aliran kecepatan rendah, yang merupakan situasi umum dalam aliran media berpori (Ho dan Webb, 2006). Penelitian ini nantinya akan memfokuskan pada fenomena aliran fluida pada retakan lapisan batubara pada proses produksi ECBM.

Aliran fluida pada retakan dipengaruhi oleh beberapa parameter, diantaranya adalah porositas, saturasi (apabila aliran terdiri dari dua fasa) dan permeabilitas. Dalam penelitian ini pengaruh saturasi gas saat proses injeksi gas karbondioksida ingin dilihat, sehingga pengaruh efek saturasi gas diperlukan dalam model. Selain itu, efek permeabilitas juga ingin diperhitungkan mengingat permeabilitas adalah salah satu faktor penentu laju alir sepanjang retakan. Model yang akan digunakan nantinya adalah model yang mencakup aliran gas $\left(\mathrm{CH}_{4}\right.$ dan $\left.\mathrm{CO}_{2}\right)$, pengaruh saturasi gas, permeabilitas, dan porositas yang merupakan faktor-faktor berpengaruh 
terhadap laju alir dalam retakan lapisan batubara. Persamaan diferensial yang menggambarkan aliran fluida dalam sistem retakan batubara didasarkan pada kombinasi hukum Darcy dan persamaan kontinuitas. Model matematika yang digunakan merupakan modifikasi model yang diusulkan oleh Guo dkk. (2003) serta Shi dan Durucan (2008). Model ini dipilih karena mempertimbangkan adanya pengaruh saturasi gas, permeabilitas dan porositas. Model persamaan matematik aliran fluida dalam sistem retakan batubara yang dibangun dan digunakan dalam simulasi model adalah sebagai berikut:

$\nabla[k \cdot M \cdot \nabla P+$ Mbar.g. $\nabla z]=\varphi \frac{\partial}{\partial t}(S)$

$M$ dan Mbar adalah permeabilitas relatif total atau total mobility yang dihitung berdasarkan hubungan saturasi gas, viskositas dan densitas dari masing-masing gas, yaitu:

$M=\frac{S^{2}}{\mu_{-} \mathrm{CO}_{2}}+\frac{(1-S)^{2}}{\mu_{-} \mathrm{CH}_{4}}$

Mbar $=\frac{\rho_{-} \mathrm{CO}_{2} \cdot \mathrm{S}^{2}}{\mu_{-} \mathrm{CO}_{2}}+\frac{\rho_{\mathrm{CH}_{4}} \cdot(1-S)^{2}}{\mu_{\mathrm{CH}_{4}}}$

Saturasi menjadi salah satu parameter penting karena pengaruh dari fluida yang terlibat dalam sistem proses $\left(\mathrm{CH}_{4}\right.$ dan $\left.\mathrm{CO}_{2}\right)$. Hubungan saturasi gas adalah sebagai berikut: $\mathrm{S}_{\mathrm{CH} 4}+\mathrm{S}_{\mathrm{CO} 2}=1.0$

Asumsi yang digunakan dalam model adalah coalbed sepenuhnya terdiri dari gas metana $\left(\mathrm{CH}_{4}\right)$, porositas dalam sistem retakan batubara tidak berubah terhadap tekanan, temperatur tetap konstan, retakan terdistribusi seragam, dan aliran gas melalui retakan mengikuti hukum Darcy.

Sistem yang diamati dan dipelajari adalah aliran retakan pada lapangan ECBM. Langkah pertama penelitian ini adalah pembuatan geometri retakan pada lapangan ECBM yang akan dipelajari dengan sistem dua dimensi oleh pembentukan grid yang merupakan domain perhitungan dilakukan dengan menggunakan software FlexPDE 5. Bentuk geometri uji skema model ditunjukkan pada Gambar 1.

Gambar 2 menunjukkan struktur grid yang dibentuk pada penelitian ini. Pada tahap komputasi diselesaikan persamaan diferensial yang menggambarkan aliran dalam sistem retakan batubara didasarkan pada kombinasi hukum Darcy dan persamaan kontinuitas, dengan menggunakan metode Finite Element Method (FEM). Kondisi awal sistem yakni pada saat $\mathrm{t}=0$, maka $\mathrm{S}=0$ (lapangan CBM terisi sepenuhnya oleh gas metana), dan tekanan sistem sama dengan tekanan reservoir $\left(\mathrm{P}=\mathrm{P}_{\text {reservoir}}\right)$. Kondisi batas sistem ditentukan mulai $\mathrm{t}=0$ sampai dengan $\mathrm{t}=100$.

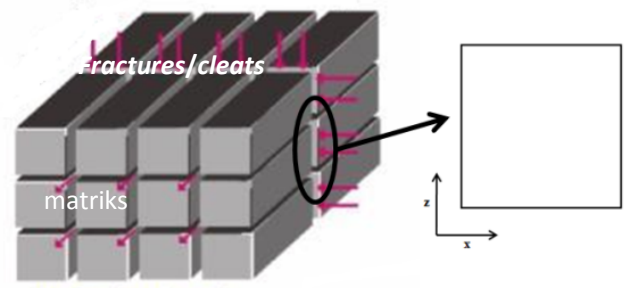

Gambar 1. Skema pemodelan matematik aliran dalam retakan

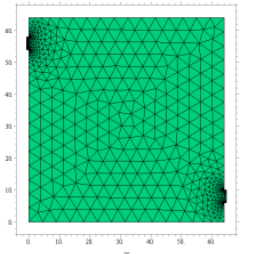

Gambar 2. Struktur grid pemodelan matematik aliran dalam retakan

Variasi yang dilakukan dalam penelitian ini adalah variasi terhadap nilai porositas retakan sebesar 0,017; 0,1; 0,206; dan 0,63 dimana nilai tersebut merupakan rentang nilai porositas retakan pada lapangan batubara subbituminous yang merupakan jenis umum lapangan batubara di Indonesia (Harris dkk., 2007). Selain itu dilakukan pula variasi terhadap luas area lapangan ECBM uji yakni 0,$5 ; 1 ; 2$; dan 4 acre, dan variasi tekanan injeksi $\mathrm{CO}_{2}$ dan tekanan produksi $\mathrm{CH}_{4}$ yang digunakan. Perhitungan ini menghasilkan profil aliran kecepatan darcy, profil tekanan dan profil perolehan metana terhadap perubahan waktu.

\section{Hasil dan Pembahasan}

Hasil prediksi simulasi disajikan dalam bentuk simulasi saturasi gas, simulasi distribusi tekanan dan simulasi kecepatan Darcy aliran dalam lapangan ECBM. Perhitungan simulasi menghasilkan profil aliran kecepatan Darcy, profil tekanan dan profil perolehan metana terhadap perubahan waktu. Simulasi saturasi gas, distribusi tekanan dan aliran pada $\mathrm{t}=0$ dan $\mathrm{t}=100$ hari ditunjukkan pada Gambar 3, Gambar 4, dan Gambar 5. 


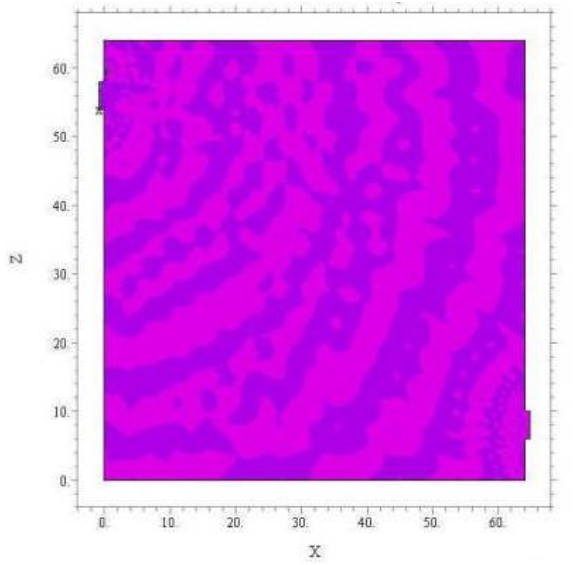

(a)

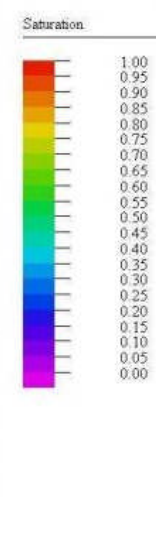

simulasi saturasi gas aliran dalam retakan

(a) $t=0$ hari (b) $t=100$ hari

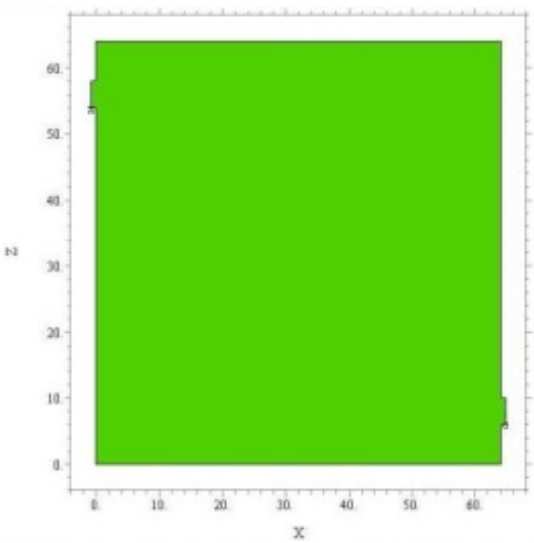

(a)

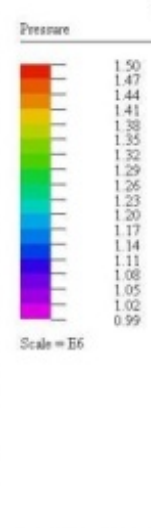

ulasi distribusi tekanan aliran dalam retakan (a) $t=0$ hari (b) $t=100$ hari

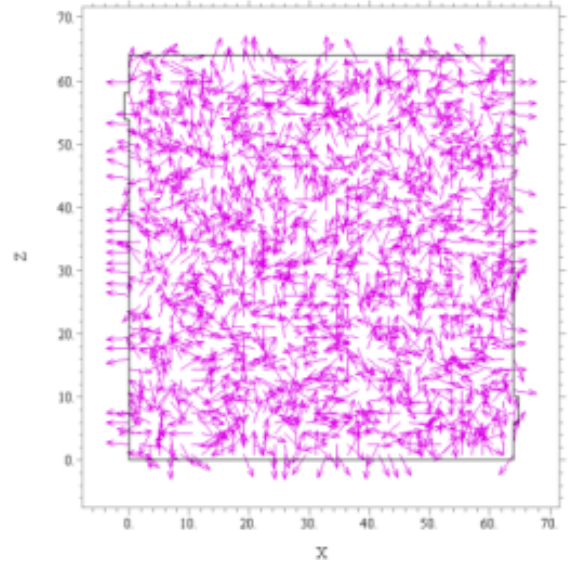

(a)

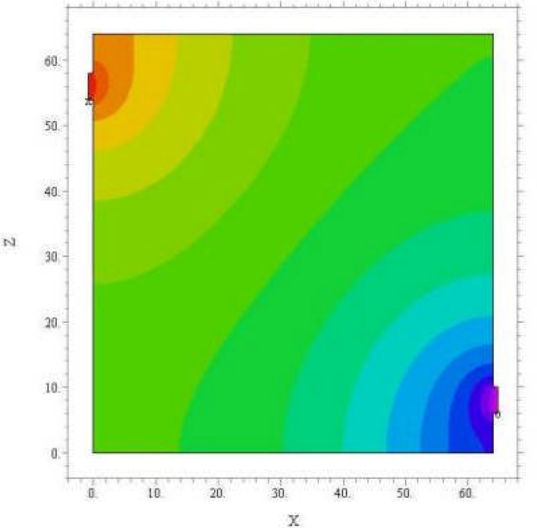

(b)

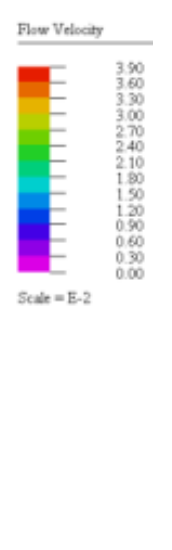

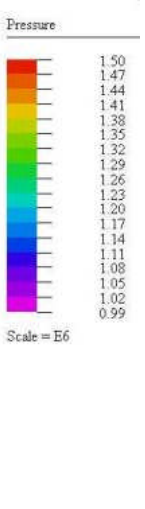

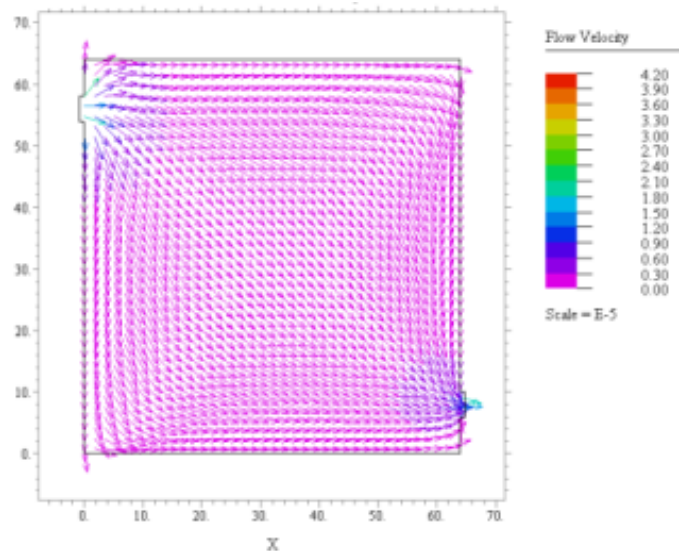

(b) (a) $t=0$ hari (b) $t=100$ hari

\subsection{Profil Kecepatan Darcy}

Gambar 6, Gambar 7, dan Gambar 8 menunjukkan pengaruh variasi uji terhadap profil kecepatan Darcy.
Gambar 6 menunjukkan pengaruh nilai porositas retakan terhadap profil kecepatan Darcy pada titik lubang injeksi dan produksi. Secara umum simulasi variasi nilai porositas menghasilkan bentuk profil yang sama, 
namun hanya berbeda pada waktu terjadinya anomali profil kecepatan Darcy. Anomali profil yang menurun secara signifikan pada lubang produksi terjadi karena efek injeksi gas $\mathrm{CO}_{2}$ pada proses ECBM. Fenomena tersebut terjadi pada saat gas $\mathrm{CO}_{2}$ yang diinjeksikan ke dalam lapangan $\mathrm{CBM}$ untuk mendorong keluar gas metana $\left(\mathrm{CH}_{4}\right)$ menyebabkan kedua gas tersebut mengalami pencampuran di dalam reservoir menjadi gas multi komponen $\left(\mathrm{CO}_{2}-\mathrm{CH}_{4}\right)$, dan fenomena perubahan profil kecepatan Darcy terjadi pada saat campuran gas tersebut mencapai titik lubang produksi untuk pertama kalinya. Akibatnya, profil pada masing-masing titik injeksi dan produksi mengalami penurunan karena pada titik injeksi dorongan yang dibutuhkan oleh gas karbondioksida untuk mendorong keluar gas metana tidak sebesar

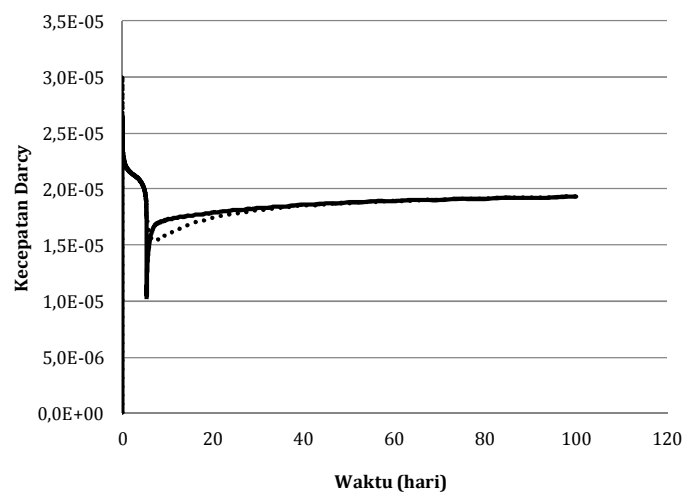

a. Porositas 0,017

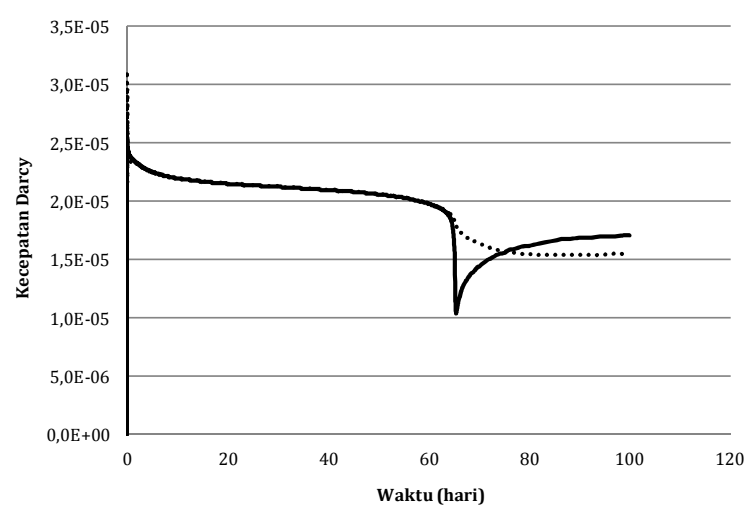

c. Porositas 0,206 pada saat kondisi lapangan CBM awal dimana lapangan CBM terisi penuh oleh gas metana. Begitupun pada titik produksi, dimana gas yang keluar sudah tidak merupakan gas metana murni, melainkan sudah merupakan gas campuran antara metana dengan sedikit karbondioksida. Perbedaan waktu terjadinya anomali menjelaskan bahwa makin besar nilai porositas retakan pada lapangan CBM/ECBM, maka ruang kosong pada rekahan tersebut akan makin besar yang menyebabkan gas metana bebas yang mengisi ruang tersebut akan semakin banyak. Begitu pula dengan profil dinamik kecepatan Darcy pada variasi nilai luas lapangan ECBM (Gambar 7), dimana makin besar luas lapangan maka akan makin besar pula gas metana bebas yang mengisinya. Hal ini dipertegas dengan profil perolehan metana pada Gambar 13 dan Gambar 14.

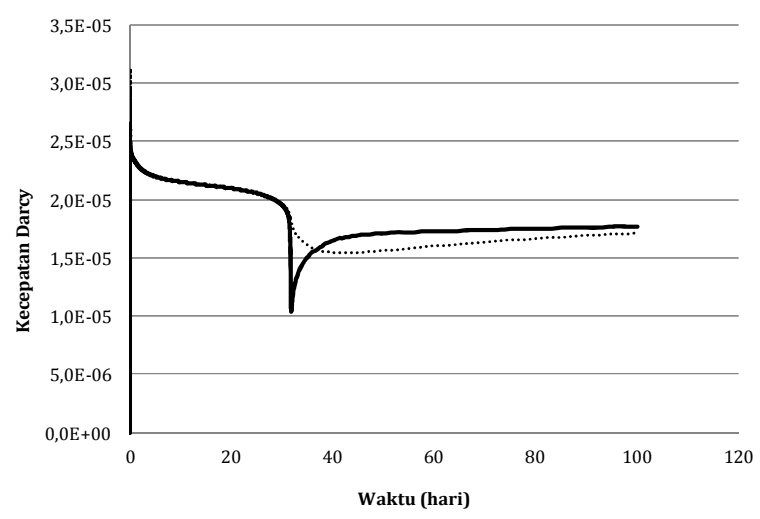

b. Porositas 0,1

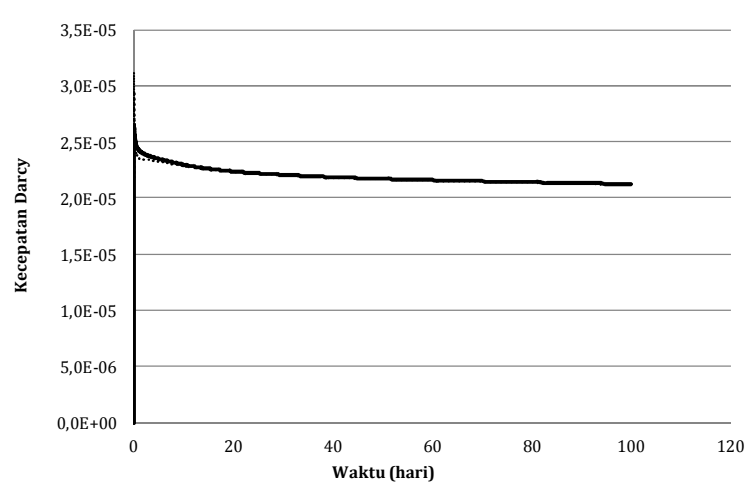

d. Porositas 0.63

Gambar 6. Profil dinamik kecepatan Darcy pada variasi nilai porositas (--- lubang injeksi, lubang produksi) 


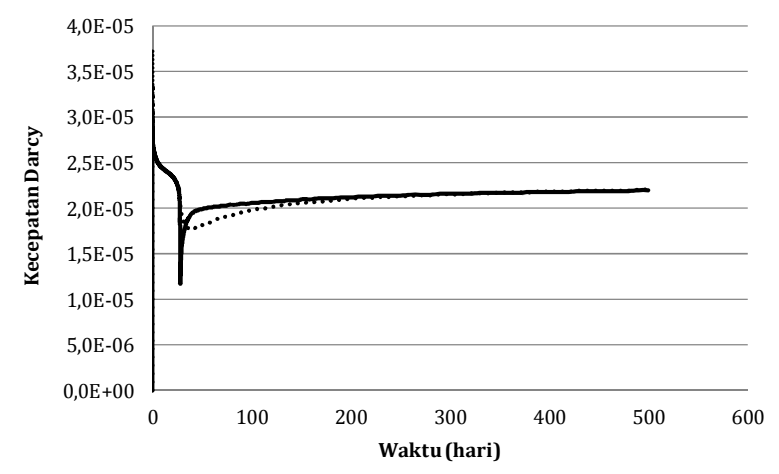

a. Luas Lapangan 0,5 acre

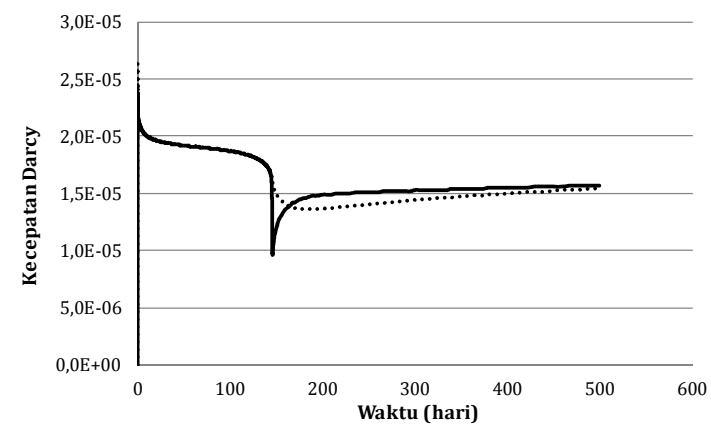

c. Luas Lapangan 2 acre

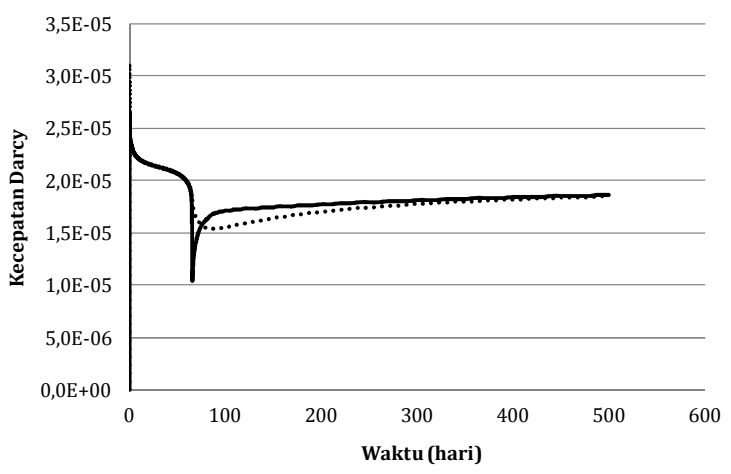

b. Luas Lapangan 1 acre

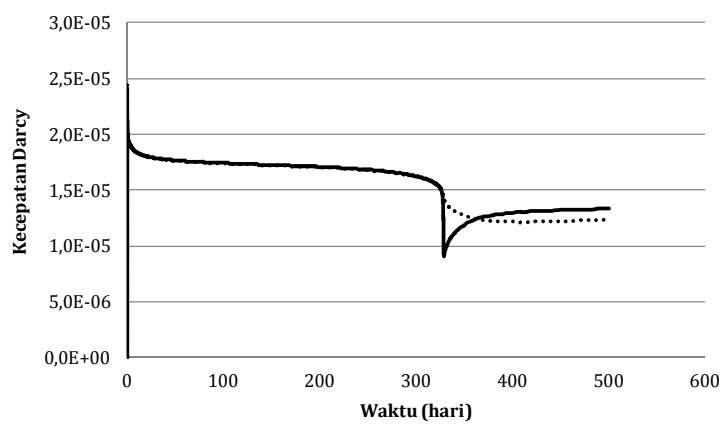

d. Luas Lapangan 4 acre

Gambar 7. Profil dinamik kecepatan Darcy pada variasi nilai luas lapangan ECBM (--- lubang injeksi, -lubang produksi)

Gambar 8 menunjukkan pengaruh variasi tekanan injeksi $\mathrm{CO}_{2}$ dan tekanan produksi $\mathrm{CH}_{4}$ pada titik lubang injeksi dan produksi. Dari profil dapat diketahui bahwa makin besar tekanan injeksi-produksi maka profil kecepatan Darcy akan makin bergeser ke kiri. Hal ini menjelaskan bahwa dengan makin besarnya tekanan injeksi-produksi yang digunakan maka proses injeksi dan perolehan pada proses ECBM akan berlangsung semakin cepat.

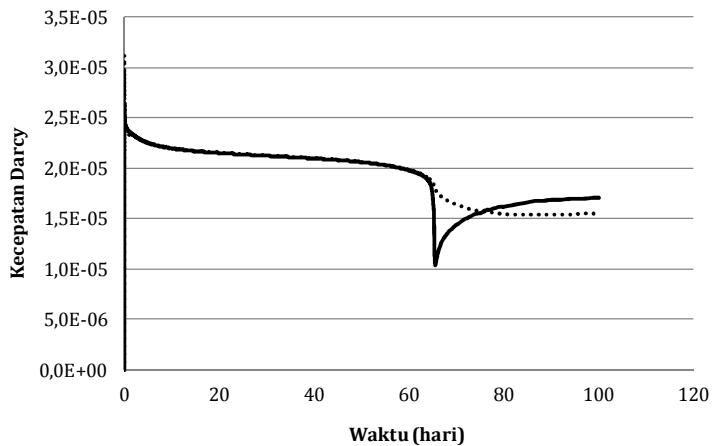

a. Tekanan injeksi 1,5 MPa, tekanan produksi 1 MPa

\subsection{Profil Tekanan dalam Lapangan ECBM}

Profil distribusi tekanan diamati pada beberapa titik uji, yakni titik lubang injeksi, titik lubang produksi, dan titik-titik di bagian ujung/sudut dari lapangan ECBM. Titik-titik pengamatan dalam profil tekanan ditunjukkan pada Gambar 9. Gambar 10, Gambar 11, dan Gambar 12 menunjukkan pengaruh variasi uji terhadap profil tekanan.

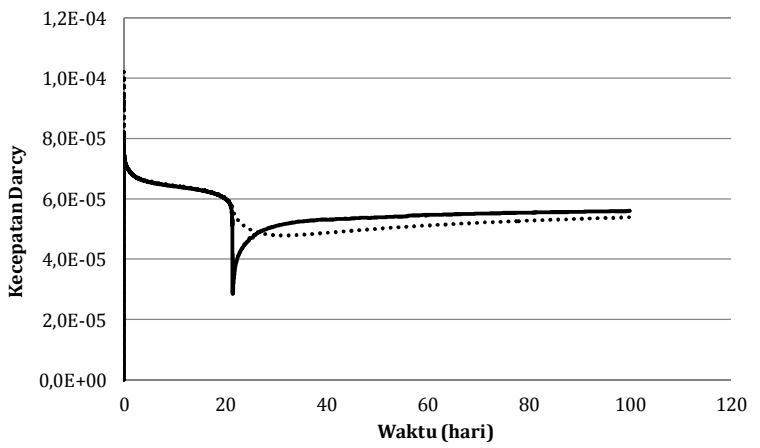

b. Tekanan injeksi 3MPa, tekanan produksi 1,5 MPa 


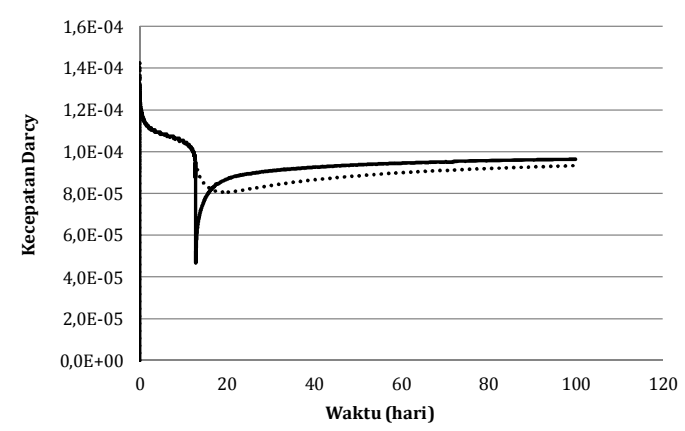

c. Tekanan injeksi $5 \mathrm{MPa}$, tekanan produksi 2,5 MPa

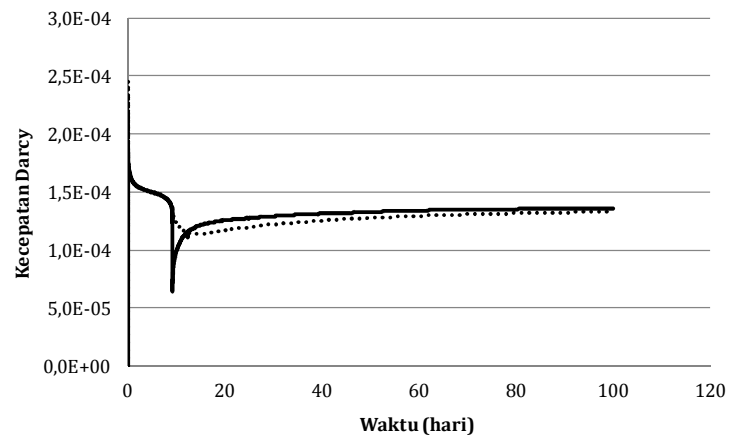

d. Tekanan injeksi 7Mpa, tekanan produksi 3,5 MPa

Gambar 8. Profil dinamik kecepatan Darcy pada variasi tekanan injeksi $\mathrm{CO}_{2}$ dan tekanan produksi $\mathrm{CH}_{4}$ (--- lubang injeksi, -lubang produksi)

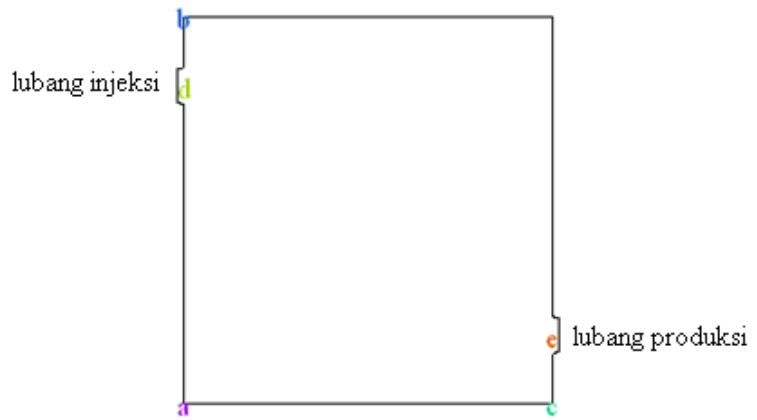

Gambar 9. Titik-titik pengamatan profil tekanan dalam simulasi reservoir ECBM

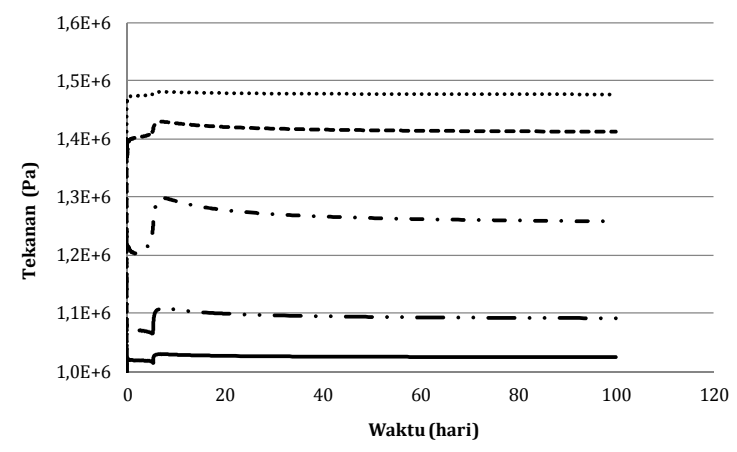

a. Porositas 0,017

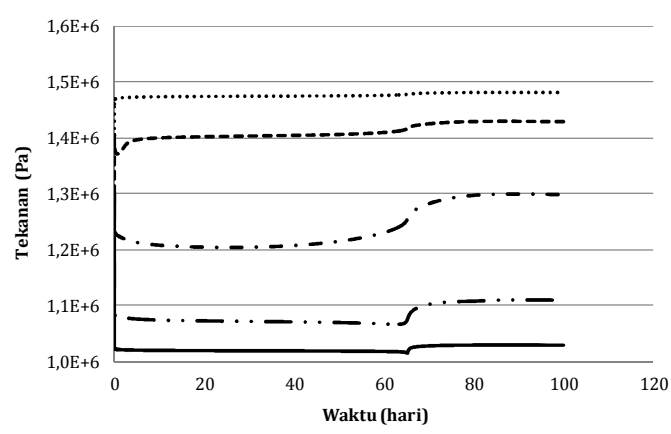

c. Porositas 0,206

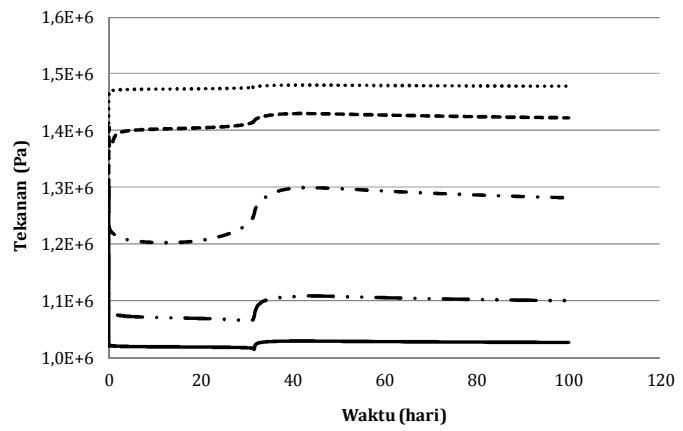

b. Porositas 0,1

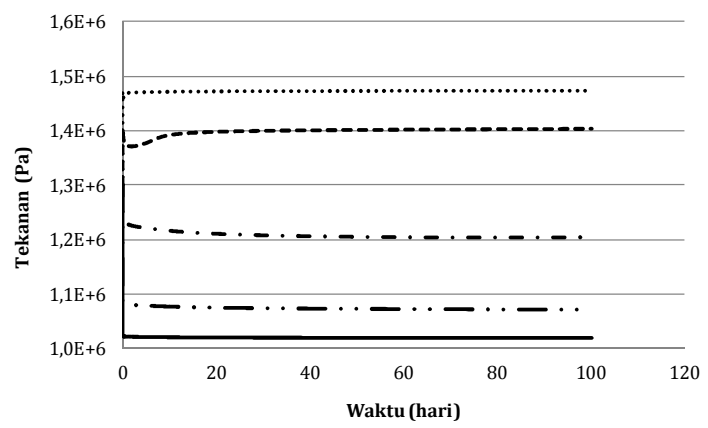

d. Porositas 0.63

Gambar 10. Profil dinamik tekanan pada variasi nilai porositas ( . . l lubang injeksi, - - - titik $(0$, zmax $),-\bullet-$ titik $(0,0),-\cdots$ titik (xmax, 0), - lubang produksi) 


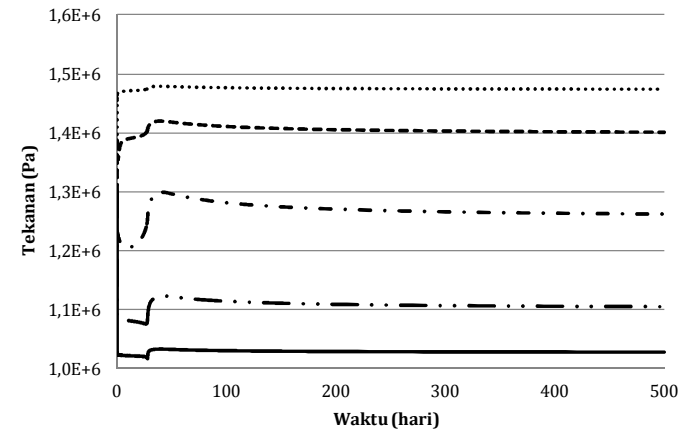

a. Luas Lapangan 0,5 acre

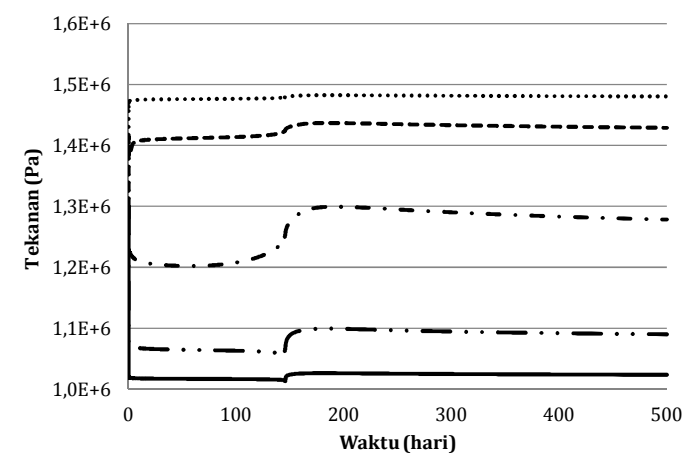

c. Luas Lapangan 2 acre

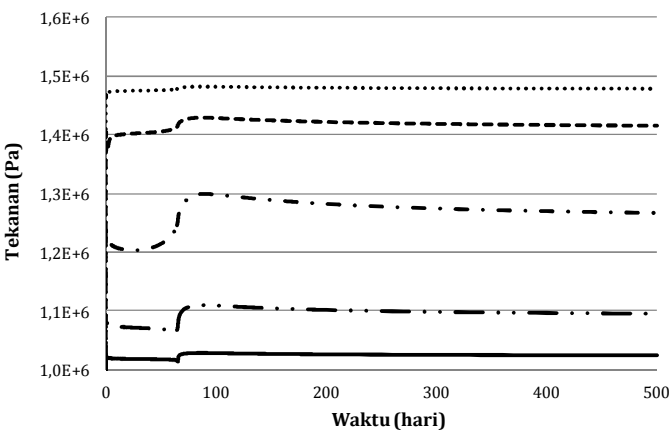

b. Luas Lapangan 1 acre

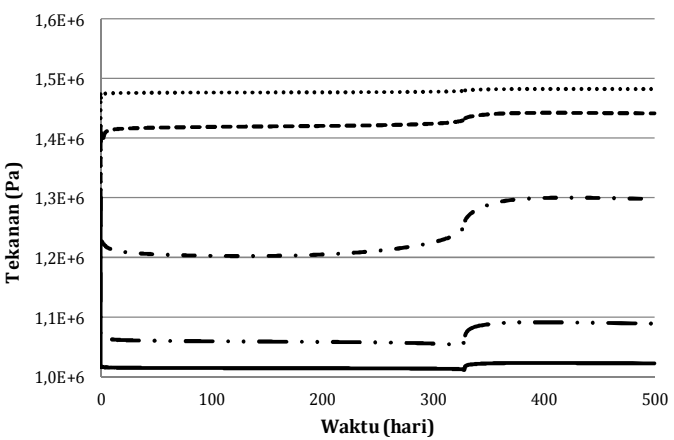

d. Luas Lapangan 4 acre

Gambar 11. Profil dinamik tekanan pada variasi nilai luas lapangan ECBM (... lubang injeksi, - - - titik (0, zmax), - • - titik $(0,0),-\cdots$ titik (xmax, 0), - lubang produksi)

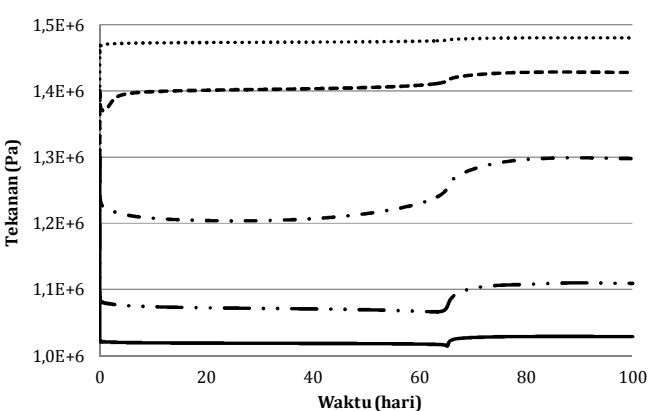

a. Tekanan injeksi 1,5 MPa, tekanan produksi $1 \mathrm{MPa}$

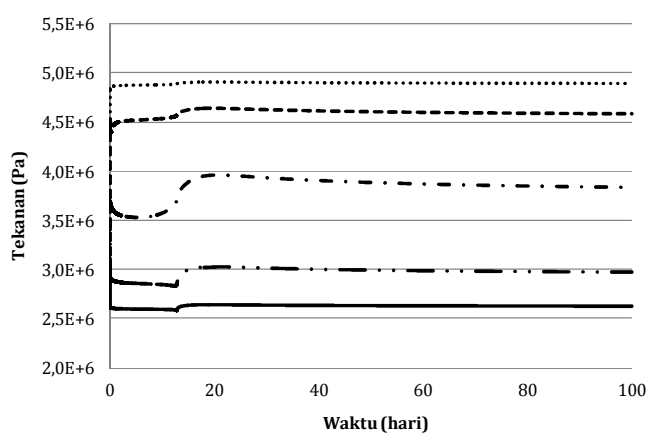

c. Tekanan injeksi 5MPa, tekanan produksi 2,5 MPa

Gambar 12. Profil dinamik tekanan pada variasi tekanan injeksi $\mathrm{CO}_{2}$ dan tekanan produksi $\mathrm{CH}_{4}$ (... lubang injeksi, - - - titik $(0$, zmax $)$, - - titik $(0,0),-\cdots$ titik (xmax, 0), - lubang produksi)

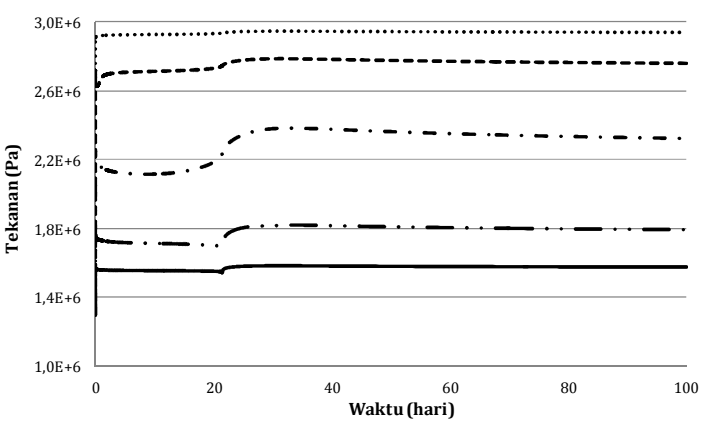

b. Tekanan injeksi 3MPa, tekanan produksi 1,5 MPa

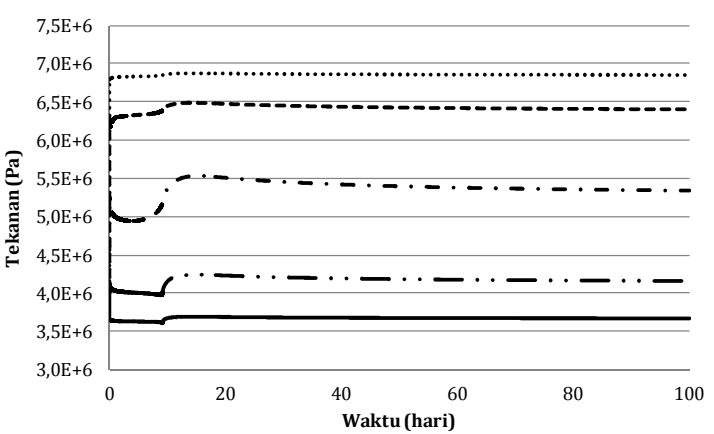

d. Tekanan injeksi 7Mpa, tekanan produksi 3,5 MPa 
Dari profil-profil tekanan terhadap masing-masing variasi uji tersebut dapat dilihat bahwa profil dinamik tekanan pada titik lubang injeksi dan produksi tidak mengalami perubahan yang signifikan, hal ini disebabkan oleh tekanan pada masing-masing titik tersebut dijaga tetap konstan, yakni 1,5 MPa untuk injeksi dan $1 \mathrm{MPa}$ pada lubang produksi. Perubahan profil tekanan terjadi pada titik pengamatan $(0,0)$; $(0, \mathrm{zmax})$; dan (xmax,0), dimana profil tekanan pada masingmasing titik tersebut mengalami peningkatan lalu kemudian cenderung stabil atau tetap. Fenomena ini terjadi bersamaan dengan fenomena menurunnya profil kecepatan Darcy pada lubang injeksi dan produksi. Hal ini menunjukkan bahwa efek injeksi gas karbondioksida $\left(\mathrm{CO}_{2}\right)$ pada proses ECBM kembali berpengaruh. Ini disebabkan tekanan lapangan/reservoir ECBM yang berisi gas metana mengalami pendesakan dan dorongan oleh gas karbondioksida yang diinjeksikan, hingga berada pada kondisi dimana reservoir sudah tidak didominasi oleh keberadaan gas metana dan digantikan keberadaannya oleh gas karbondioksida.

\subsection{Profil Perolehan Metana}

Gambar 13, 14, dan 15 menunjukkan pengaruh variasi uji terhadap profil tekanan. Berdasarkan profil perolehan metana pada masing-masing variasi uji di atas dapat diketahui bahwa makin besar nilai porositas maka waktu perolehan metana yang dibutuhkan pun akan makin lama. Hal ini disebabkan karena makin besar nilai porositas retakan pada lapangan CBM/ECBM, maka ruang kosong pada rekahan tersebut akan makin besar yang menyebabkan gas metana bebas yang mengisi ruang tersebut akan semakin banyak. Begitu pula dengan profil perolehan metana pada variasi nilai luas lapangan ECBM (Gambar 14), dimana makin besar luas lapangan maka akan makin besar pula gas metana bebas yang mengisinya, sehingga waktu perolehan yang dibutuhkan akan semakin lama.

Berbeda dengan profil perolehan metana pada variasi tekanan injeksi $\mathrm{CO}_{2}$ dan tekanan produksi $\mathrm{CH}_{4}$ (Gambar 15), dimana makin besarnya tekanan injeksi-produksi yang digunakan maka proses injeksi dan perolehan pada proses ECBM akan berlangsung semakin cepat.

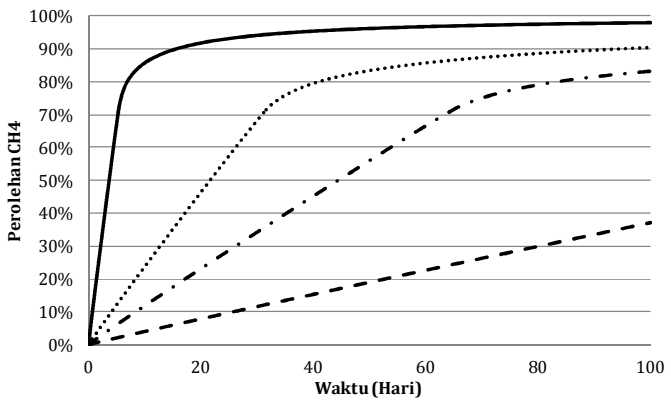

Gambar 13. Profil dinamik perolehan metana pada variasi nilai porositas (porositas $0,017, \ldots$ porositas $0,1,-$ porositas 0,206 , - - - porositas 0,63 )

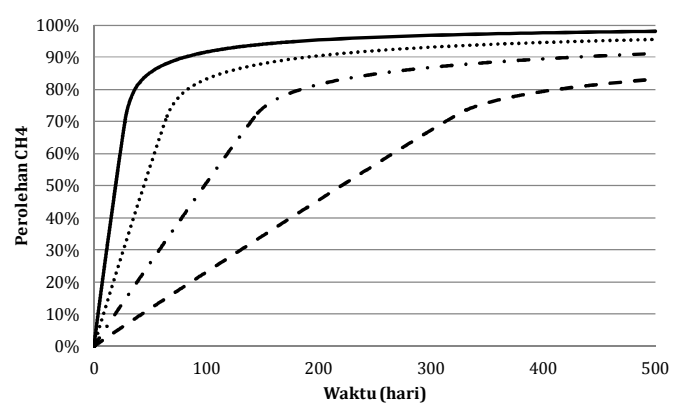

Gambar 14. Profil dinamik perolehan metana pada variasi nilai luas lapangan ECBM (- luas lapangan 0,5 acre, ... luas lapangan 1 acre, - - - luas lapangan 2 acre, - - luas lapangan 4 acre)

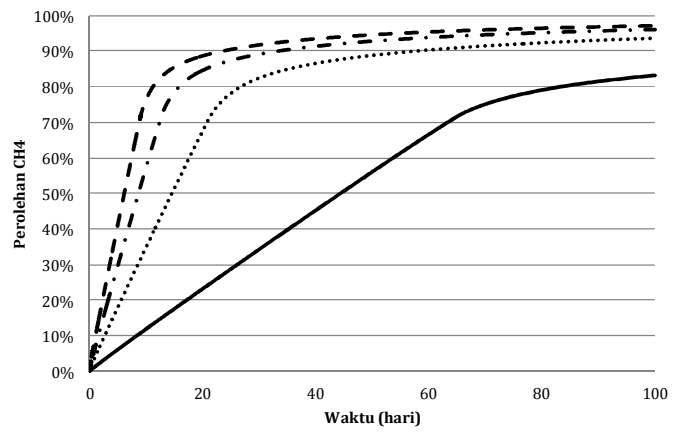

Gambar 15. Profil dinamik perolehan metana pada variasi tekanan injeksi $\mathrm{CO}_{2}$ dan tekanan produksi $\mathrm{CH}_{4}(-1,5 \mathrm{MPa}$ dan 1MPa, ... 3MPa dan 1,5MPa, - - 5 MPa dan 2,5MPa, - - 7MPa dan 3,5 MPa)

\section{Kesimpulan}

Mekanisme aliran fluida dalam retakan dengan injeksi $\mathrm{CO}_{2}$ pada proses ECBM telah dikaji dengan cara pendekatan model dan simulasi. Dari hasil penelitian diketahui bahwa mekanisme tersebut dipengaruhi oleh 
beberapa variabel, yaitu porositas $(\phi)$, permeabilitas $(k)$, dan saturasi gas $(S)$.

Model matematika yang mempertimbangkan variabel-variabel tersebut dan mampu menjelaskan mekanisme aliran fluida dalam retakan dengan injeksi $\mathrm{CO}_{2}$ pada proses ECBM adalah modifikasi model yang dikembangkan dalam penelitian, yaitu persamaan 3, yaitu:

$$
\nabla[k \cdot M \cdot \nabla P+\text { Mbar.g. } \nabla z]=\varphi \frac{\partial}{\partial t}(S)
$$

Dari hasil penelitian, simulasi selama 100 hari menunjukkan bahwa perolehan metana pada porositas 0,017 adalah 97,88\%; porositas 0,1 adalah 90,57\%; porositas 0,206 adalah 83,11\%; dan porositas 0,63 adalah $37,16 \%$. Secara umum makin besar porositas lapangan CBM, maka makin besar potensi perolehan $\mathrm{CH}_{4}$ pada proses ECBM dan makin besar pula potensi penyimpanan $\mathrm{CO}_{2}$ dalam lapangan tersebut. Begitu pula dengan variasi luas lapangan ECBM dan variasi tekanan injeksiproduksi, dimana makin besar luas lapangan ECBM dan tekanan injeksi-produksi yang digunakan, maka makin besar potensi perolehan $\mathrm{CH}_{4}$ pada proses ECBM dan makin besar pula potensi penyimpanan $\mathrm{CO}_{2}$ dalam lapangan tersebut.

Penelitian selanjutnya disarankan untuk melakukan penyempurnaan model dan simulasi dengan memperhitungkan dan menggabungkan model simulasi fenomena aliran di bagian mikropori (matriks) lapangan CBM. Penelitian mengenai simulasi variasi posisi dan jumlah lubang injeksi maupun produksi pada proses ECBM juga menarik untuk dikaji lebih lanjut.

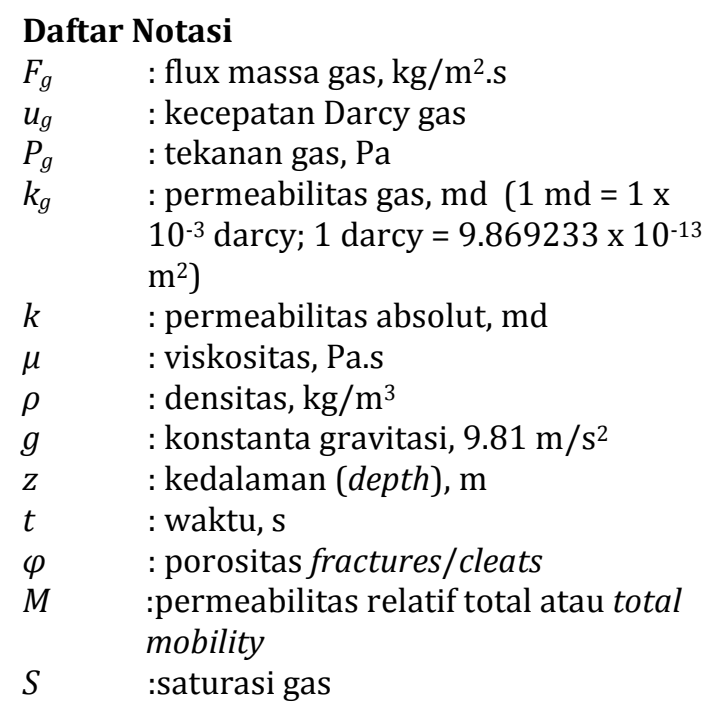

\section{Daftar Pustaka}

Boer, R., Principles and Concept Model COMMAP (Comprehensive Mitiation Assessment Process),Prosiding Seminar dan Workshop Forest and Carbon Sequestration: Business Opportunity for Private Sector, Kuala Lumpur, 10-11 Oktober 2000.

Figueroa, J. D.; Timothy, F.; Plasynski, S.; McIlvried, H.; Srivastava, R. D., Advances in $\mathrm{CO}_{2}$ capture technology-the U.S. department energy's carbon sequestration program, International Journal of Greenhouse Gas Control, 2008, 2(1), 9-20.

Gray, I., Reservoir engineering in coal seams:part 1-the physical process of gas storage and movement in coal seams, Journal Society of Petroleum Engineers Reservoir Engineering, 1987, 2(1), 28-34.

Guo, X.; Zhimin D.; Shilun, L., Computer Modeling and Simulation of Coalbed Methane Reservoir, Society of Petroleum Engineers Eastern Regional Meeting, Pittsburgh, Pennsylvania, USA, 6-10 September 2003.

Harris, J. M.; Kovscek, A. R.; Orr, F. M. Jr.; Zoback, M. D., Geologic Storage of $\mathrm{CO}_{2}$; Energy Resources Engineering: USA, 2007.

Ho, C. K.; Webb, S. W., Gas Transport in Porous Media; Springer: Dordrecht, Netherlands, 2006.

Kheshgi, H.; Cappelen, F.; Lee, A.; Crookshank, S.; Heilbrunn, A.; Mikus, T.; Robson, W.; Senior, B.; Stileman, T.; Warren, L., Carbon Dioxide Capture and Geological Storage: Contributing to Climate Change Solutions, Prosiding SPE International Health, Safety \& Environment Conference, Abu Dhabi, UAE, 2-4 April 2006.

Law, D. H. S.; van der Meer, L. G. H.; Gunter, W. D., Numerical Simulator Comparison Study for Enhanced Coalbed Methane Recovery Processes, Part I: Pure Carbon Dioxide Injection, Prosiding SPE Gas Technology Symposium, Calgary, 30 April-2 May 2002.

Lemigas, Coalbed Methane, http://www.lemigas.esdm.go.id/371.htm (Akses tanggal 18 Mei 2010) 
Mazzotti, M.; Pini, R.; Storti, G., Enhanced coal bed methane recovery, The Journal of Supercritical Fluids, 2009, 47(3), 619-617.

Olivier, J. G. J.; Peters, J. A. H. W., No Growth in Total Global $\mathrm{CO}_{2}$ Emissions in 2009, Netherlands Environmental Assessment Agency: Netherlands, 2010.

Pini, R., Enhanced Coal Bed Methane Recovery Finalized to Carbon Dioxide Storage. Dissertation, ETH Zurich, Zurich, Switzerland, 2009.

Raharjo, I. B., Mengenal CBM (Coal Bed Methane), http://imambudiraharjo. wordpress.com/2010/01/19/mengenal-cbmcoal-bed-methane/(akses tanggal 18 Mei 2010)
Shi, J. Q.; Durucan, S., Modeling of Mixed-Gas Adsorption and Diffusion in Coalbed Reservoirs, Prosiding SPE Unconventional Reservoirs Conference, Keystone, Colorado, USA, 10-12 February 2008.

Weart, S. R., The Discovery of Global Warming; Harvard University Press: USA, 2008.

White, C. M.; Smith, D. H.; Jones, K. L.; Goodman, A. L.; Jikich, S. A.; LaCount, R. B.; DuBose, S. B.; Ozdemir, E.; Morsi, B. I.; Schroeder, K. T., Sequestration of carbon dioxide in coal with enhanced coalbed methane recovery-a review, Energy Fuels, 2005, 19(3), 659-724. 